\title{
Non-metal-requiring Catalyst Contained in Recovered Methyl Linolenate from an Autoxidizing Sample
}

\author{
Makio MoRITA \\ Department of Food and Nutrition, Japan Women's University, \\ 2-8-1 Mejirodai, Bunkyo-ku, Tokyo 112, Japan
}

Received November 5, 1980

\begin{abstract}
Non-metal-requiring catalysts in recovered methyl linolenate from an autoxidizing sample were unstable on contact with silicic acid and the activity varied widely with the way of recovery, countercurrent extraction and column chromatography under different conditions. After reduction with stannous chloride, a substance was found which was characteristically present in the products derived from the recovered methyl linolenate high in the catalytic activity. It was tentatively identified by MS, IR, OsO $\mathrm{O}_{4}$ oxidation- $\mathrm{IO}_{4}{ }^{-}$oxidation, and $\mathrm{LiAlH}_{4}$ reduction- $\mathrm{IO}_{4}{ }^{-}$oxidation as methyl 9,13-dihydroxy-10-epoxy-15-octadecenoate.
\end{abstract}

Autoxidizing lipids contain autocatalytic materials which act in further autoxidation even in the absence of transition metals., ${ }^{1,2}$ We have called them non-metal-requiring catalysts.

This paper deals with the isolation and identification of a reduced product, possibly from the non-metal-requiring catalysts of lowpolarity in autoxidizing methyl linolenate; the presence of such catalysts has been preliminarily reported by us. ${ }^{3)}$

\section{MATERIALS AND METHODS}

Methyl linolenate. Free fatty acid mixture of linseed oil in acetone was fractionated by chilling to $-73 \sim 78^{\circ} \mathrm{C}$ and the obtained linolenic acid was methylated and purified as previously described. ${ }^{3)}$ Purity: linolenate $85 \%$ and linoleate $15 \%$. The methyl linolenate was shaken in contact with air at room temperature in the dark. The sample of which the peroxide content reached about $800 \mu \mathrm{eq} / \mathrm{ml}$ was used in further work.

Recovering of methyl linolenate. The autoxidizing linolenate sample $(15 \mathrm{ml})$ was separated by a countercurrent extraction in ten successive $200 \mathrm{ml}$ separate funnels containing $80 \mathrm{ml}$ hexane and $80 \mathrm{ml}$ methanol-water $(9: 1)$, both the solvents being saturated with each other in advance. Most of methyl linolenate was contained in the hexane layers at the end and the next to the end in successive extraction without observable impurities (Sample I).
Column chromatography was carried out for the recovering of methyl linolenate in the following two ways using silicic acid prepared by washing 100 200 mesh grade particles (Kanto Chem. Co.) in water to remove too fine particles and activating at $170^{\circ} \mathrm{C}$ overnight:

(1) The autoxidizing sample $(55 \mathrm{ml})$ diluted with $220 \mathrm{ml}$ hexanc-ethyl ether $(95: 5)$ was applied to a column ( $47 \mathrm{~mm}$ in diameter) packed with $150 \mathrm{ml}$ silicic acid and the column was eluted with hexane-ethyl ether $(95: 5)$. Eluates containing methyl linolenate without impurities were combined (Sample II).

(2) The autoxidizing sample $(15 \mathrm{ml})$ diluted with $70 \mathrm{ml}$ hexane was applied to a column (23 $\mathrm{mm}$ in diameter) packed with $300 \mathrm{ml}$ silicic acid and the column was eluted with $140 \mathrm{ml}$ hexane and then with hexane-ethyl ether $(95: 5)$. Eluates containing methyl linolenate without impurities were combined (Sample III).

All the recovering procedures were performed under oxygen-free conditions made by purging with nitrogen or carbon dioxide.

Assay for catalytic activity. The oxygen uptake of the methyl linolenate recovered ( $1 \mathrm{ml}$ a vessel) was measured in the Warburg's manometry at $30^{\circ} \mathrm{C}$ for $2 \mathrm{hr}$.

Separation and identification of products. To the recovered methyl linolenate samples (100 portions) was added 2 portions of stannous chloride as a $10 \%$ ethanol solution; after $2 \mathrm{hr}$ standing at room temperature the mixture was diluted with methanol-water $(9: 1)$, and extracted twice with hexane. To the methanol layer was then added equal volumes of benzene and water. The benzene layer was repeatedly washed with water, concentrated under reduced pressure, and applied to a high pressure preparative liquid chromatography: particles of 
silicic acid fine and homogeneous in size were prepared by purverizing silicic acid for chromatography (Kanto Chemical Co.) and by repeated collecting particles which sedimented during $1.5 \sim 3 \mathrm{hr}$ standing in water $20 \mathrm{~cm}$ deep.

Gas-liquid-partition chromatography (GLC) was carried out on a Shimadzu GC-6A model under the following conditions: Column, $3 \mathrm{~mm} \times 2 \mathrm{~m}$ glass column packed with $3 \%$ OV-1 on Chromosorb W (HP) for trimethylsilyl (TMS) derivatives and $15 \%$ polyethyleneglycol adipate on Chromosorb WAW (DMCS) for propanal; carrier gas, $\mathrm{N}_{2}$ for analysis and $\mathrm{He}$ for preparative use $(50 \mathrm{ml} / \mathrm{min})$; detector, flame ionization for analysis and thermal conductivity for preparative use; temperature, $230^{\circ} \mathrm{C}$ or 200 to $300^{\circ} \mathrm{C}$ at a rate of $2^{\circ} \mathrm{C} / \mathrm{min}$ for TMS-derivatives and $50^{\circ} \mathrm{C}$ for propanal.

Samples to be converted to TMS-derivatives were dissolved in a TMS-reagent (TMS-HT, Tokyo Kasei Co., trimethylchlorosilan and hexamethyldisilazan in pyridine) and injected into the gas chromatograph without separation of the derivatives.

Samples gas-chromatographically separated were applied to a Hitachi mass spectrometer RMU -6 using the direct inlet system (inlet temperature $150^{\circ} \mathrm{C}$, and ionizing potential $70 \mathrm{eV}$ ). Infrared spectra were taken in films on a potassium bromide plate.

Osmium tetroxide oxidation was carried out according to Niehaus and Ryhage, ${ }^{4)}$ the oxidized sample (below $2 \mathrm{mg}$ ) was dissolved in dioxane $(1 \mathrm{ml})$, to the solution was added periodic acid ( $2 \mathrm{mg}$ to $1 \mathrm{ml}$ ), and after $1 \mathrm{hr}$ standing the solution was directly injected into the gas chromatograph. Propanal was eluted before dioxane.

In order to open the epoxy ring reductively, a sample (below $2 \mathrm{mg}$ ) was refluxed with lithium aluminum hydride $(20 \mathrm{mg})$ in dry tetrahydrofuran $(5 \mathrm{ml})$ overnight, the residual reagent was decomposed with hydrochloric acid, and the product was repeatedly extracted with ethyl ether. The ether extract was evaporated and applied to a Toyo filter paper No. 50. The paper was developed with benzene-ethyl acetate-methanol-water $(10: 10: 5: 1 \mathrm{v} / \mathrm{v})$ and polyols were detected by spraying with ammoniacal silver nitrate followed by heating at $105 \sim 110^{\circ} \mathrm{C}$. The reference compounds, 1,9,10,12,13-pentahydroxyoctadecan and 1,9,10-trihydroxyoctadecan, were prepared from methyl linoleate and methyl oleate, respectively, by reduction with lithium aluminum hydride followed by osmium tetroxide oxidation.

The epoxy-ring-opened sample was treated with periodic acid $(2 \mathrm{mg})$ in ether $(1 \mathrm{ml})$ for $1 \mathrm{hr}$, washed with water, the ether layer was diluted with $5 \mathrm{ml}$ ethanol, to the solution was added sodium borohydride $(20 \mathrm{mg})$, the solution was allowed to stand overnight, a drop of acetic acid was added, and the product was extracted with ether. The product was converted to TMS-derivatives and analyzed in the GLC.

\section{RESULTS AND DISCUSSION}

In their susceptibility to autoxidation in the absence of added metal catalysts, methyl linolenate samples recovered from autoxidizing methyl linolenate widely varied according to the methods employed for recovery. Samples I which had been recovered by a countercurrent extraction using hexane-methanol containing water showed rapid oxygen uptake in the Warburg's manometry $(4.27 \mu \mathrm{mol} / \mathrm{hr})$ and sample II which had been recovered by both application to and elution from a short silicic acid column using a hexane -ethyl ether solvent of 95:5 showed intermediate oxygen uptake $(1.35 \mu \mathrm{mol} / \mathrm{hr})$, whereas sample III which had been adsorbed in a long column from hexane and then recovered by elution with hexane-ethyl ether 95:5 oxidized slowly (oxygen uptake not observed within $2 \mathrm{hr}$ ).

The higher the oxidation rate of a sample, presumably the more the contamination of non-metal-requiring catalysts. However, I and II as well as III gave no spots of impurities on thin layer chromatograms, suggesting that the non-metal-requiring catalysts had similar mobility on thin layer chromatograms to that of methyl linolenate.

The reason why II showed rapid oxygen uptake, whereas III did not, was probably that in the case of II the non-metal-requiring catalysts were not adsorbed on silicic acid from a hexane-ethyl ether solvent, $(95 ; 5)$ and consequently not destroyed, but in the case of III they were destroyed once adsorbed from a hexane solution. Moreover, a longer size of column and slower passage of the sample seem to have carried out the inactivation of non-metal-requiring catalysts more effectively.

Treatment of the samples with stannous chloride, a reducing agent, gave many polar products probably coming from minor impurities. The products more polar than methyl linolenate were obtained by extraction with aqueous methanol and were subjected to a high pressure preparative liquid chromatography as follows: to the column $(10 \mathrm{~mm} \times 500$ $\mathrm{mm}$ ) conditioned by passing benzene was ap- 
plied each of the samples from I, II, and III (below $150 \mathrm{mg}$ ) in benzene. The column was eluted with benzene-ethyl acetate 95:5 $(100 \mathrm{ml}), \quad 90: 10 \quad(100 \mathrm{ml}), 80: 20 \quad(100 \mathrm{ml})$, $70: 30(100 \mathrm{ml}), 50: 50(100 \mathrm{ml})$, ethyl acetate $(100 \mathrm{ml})$, and methanol $(100 \mathrm{ml})$, successively, at a flow rate of $3.3 \sim 3.7 \mathrm{ml} / \mathrm{min}(27 \sim 28$ $\mathrm{kg} / \mathrm{cm}^{2}$ ).

Each set of the fractions eluted from I, II and III with the same eluant was compared among the set on GLC after conversion to TMS-derivatives. There were no observable differences in the fraction sets eluted with benzene-ethyl acetate $95: 5,90: 10,80: 20$, $70: 30$, and methanol, while in the fraction set eluted with benzene-ethyl acetate $50: 50$ I gave much more peaks and II one more peak than III.

A component present in the reduced products of I or II, but absent in those of III, is possibly what has come from a non-metalrequiring catalyst. Although there were many possible components in the benzene-ethyl acetate $(50: 50)$ eluted fraction of $I$, we gave up their isolation and identification in the present investigation because of their considerable complexity and attempts were made to isolate a component (TMS-A) in the same eluting fraction of II.

TMS-A was preparatively isolated by GLC (Fig. 1). Figure 2 shows the mass spectrum of TMS-A; $m / z: 486\left(\mathrm{M}^{+}\right), 471\left(\mathrm{M}^{+}-15\right), 455$ $\left(\mathrm{M}^{+}-31\right), 402,259,171(+173), 73$. The infrared spectrum of TMS-A was as follows:
$3,000 \sim 3,010 \mathrm{~cm}^{-1}$ (shoulder), olefinic proton; $1,748 \mathrm{~cm}^{-1}$, ester carbonyl; no other carbonyl; $970 \mathrm{~cm}^{-1}$, trans-double bond (weak). In the UV spectrum there was no absorption peak in the range $220 \sim 300 \mathrm{~nm}$, indicating the absence of conjugated diene bonds.

After treatment with sodium borohydride the TMS-A peak was not affected in GLC,

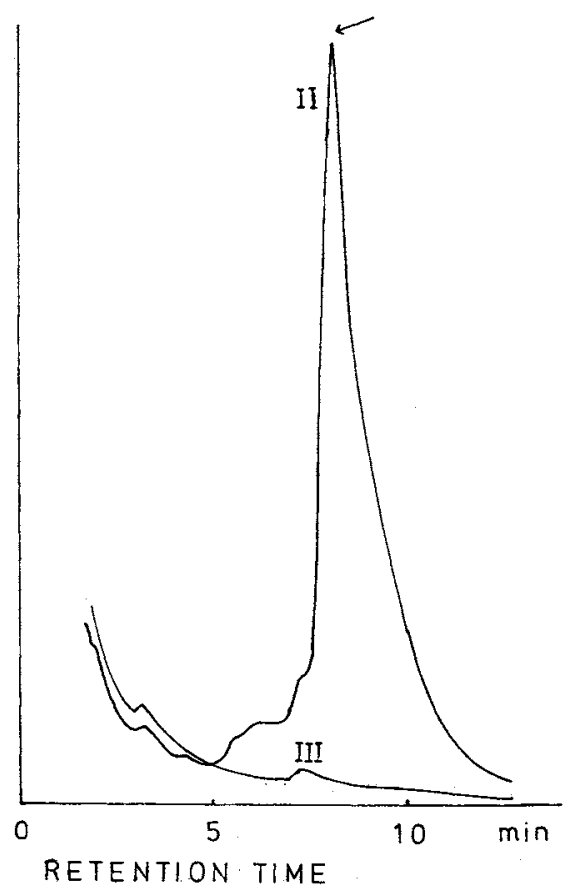

Fig. 1. Gas Chromatogram of Fraction Eluted with Benzene-Ethyl Acetate $50: 50$.

II or III represents the number of the sample from which the fraction was derived. The arrow points to indicates the peak of component (TMS-).

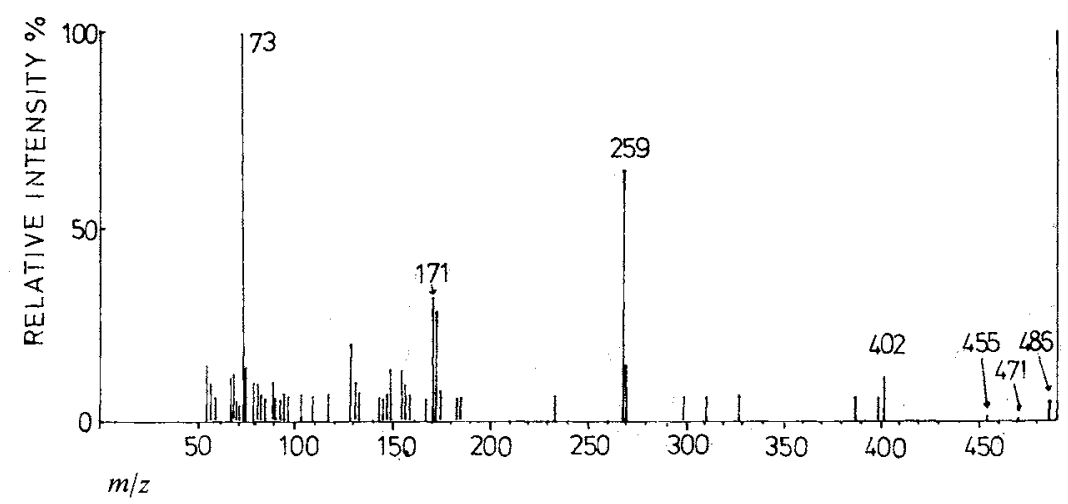

FIG. 2. Mass Spectrum of TMS-A. 


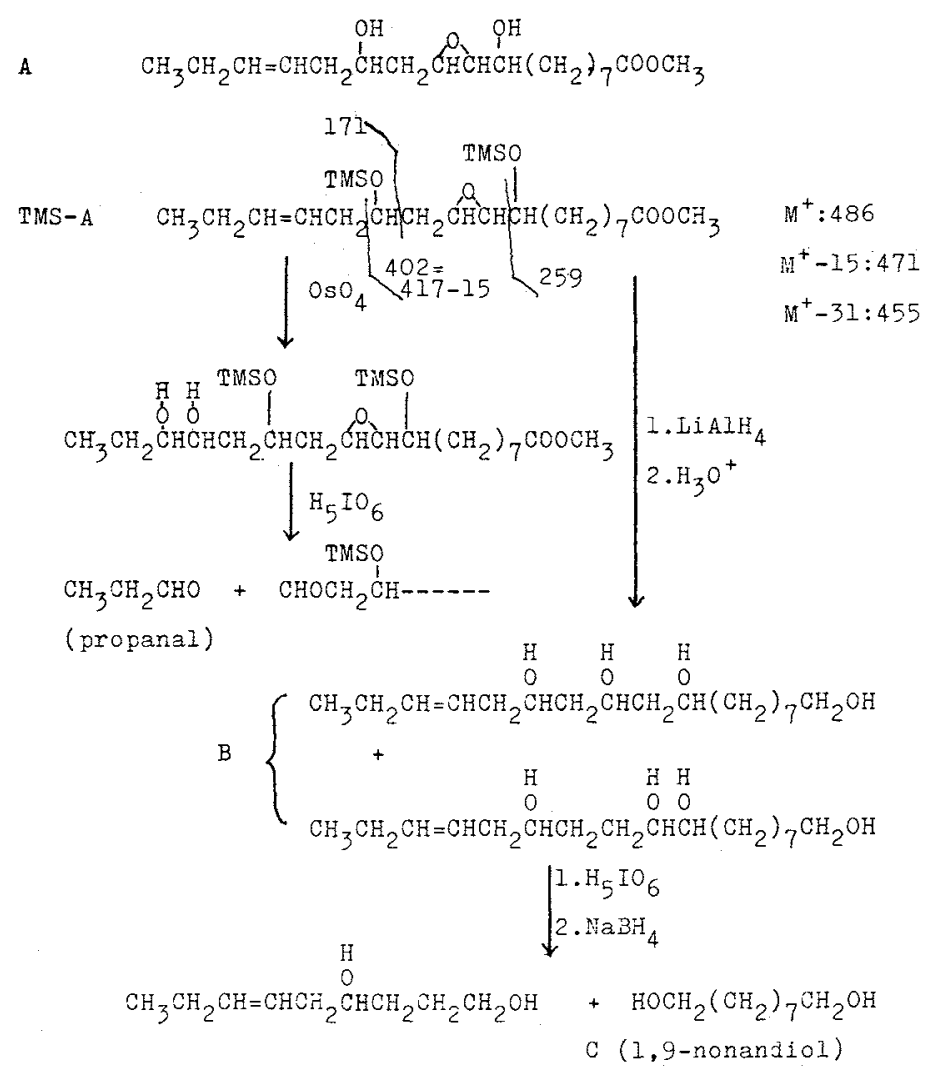

SCHEME

also indicating the absence of keto groups.

After oxidation with osmium tetroxide followed by periodate oxidation, TMS-A gave propanal on GLC. TMS-A gave a spot (B) on a paper chromatogram $(R f=0.55)$ after lithium aluminum hydride reduction. $B$ was assumed to be tetrahydroxyoctadecene in referring to $1,9,10,12,13$-pentahydroxyoctadecan $(R f=0.43)$ and 1,9,10-trihydroxyoctadecan $(R f=0.64)$. After B was purified by preparative paper chromatography (PC), oxidized with periodic acid, and reduced with sodium borohydride, a spot (C) was observed in $\mathrm{PC}$ of which the mobility was same as that of 1,9-nonandiol. After isolation by preparative PC and conversion to the TMS-derivative, $\mathrm{C}$ gave in GLC a peak of which the retention time agreed with that of 1,9-di(trimethylsiloxy)nonan prepared from 1,9-nonandiol. Gas-chromatographically separated TMS-C gave a mass spectrum which agreed with that of the authentic compound.

These results suggested that $\mathrm{A}$ was methyl 9,13-dihydroxy 10,11-epoxy 15-octadecenoate as shown in Scheme. The peak $m / z: 173$ in the mass spectrum may be attributed to an impurity which came from contaminating linoleate, as its intensity varied considerably among repeated runs of the preparation. The absorption of trans double bond in the infrared spectrum was weak and that of transepoxy group was obscured by a large peak characteristic of TMS-derivatives, and neither the double-bond nor the epoxy group could be, therefore, geometrically determined.

The parent substance of $\mathrm{A}$ is assumed to be the following compound.<smiles>CC=CCC1OOC2CC(C(=O)OC)C(CC2CCC)O1</smiles> 
There is a possibility that this compound is one of the non-metal-requiring catalyst of autoxidizing methyl linolenate. The configurations of carbons $9,10,11$, and 13 are yet unknown but must affect the stability of the endoperoxy group and consequently the catalytic activity. If the configurations favor the cleavage of the endoperoxy group the resultant diradical will act as an initiator for the chain reaction.

Acknowledgment. The author thanks Miss Harumi
Iwasaki, Mrs. Takako Sakai, Miss Sumie Nakada, and Miss Hitomi Murao for technical assistance.

\section{REFERENCES}

1) M. Morita and M. Fujimaki, Agric. Biol. Chem., 37, 1213 (1973).

2) M. Morita, M. Tanaka, Y. Takayama and Y. Yamamoto, J. Arn. Oil Chemists' Soc., 53, 487 (1976).

3) M. Morita, M. Osumi and Y. Yokoyama, Yukagaku, 26, 173 (1977).

4) W. G. Niehaus, Jr. and R. Ryhage, Anal. Chem., 40, 1840 (1968). 